\title{
Challenging the Expiry Dates of Two Mycotoxins Standards: Afla and Ochra A
}

\author{
A. Aridi', L. Baydoun², C. M. S. T. Sukhn ${ }^{2 *}$ \\ ${ }^{1}$ Chemistry Department, Faculty of Sciences II, Lebanese University, Fanar, Lebanon \\ ${ }^{2}$ Environment Core Laboratory, Pathology \& Laboratory Medicine Department, Faculty of Medicine, American University of \\ Beirut, Hamra, Beirut, Lebanon \\ Email: *cs02@aub.edu.lb,corelabs@aub.edu.lb
}

How to cite this paper: Aridi, A., Baydoun, L. and Sukhn, C.M.S.T. (2017) Challenging the Expiry Dates of Two Mycotoxins Standards: Afla and Ochra A. Journal of Materials Science and Chemical Engineering, 5, 59-68.

https://doi.org/10.4236/msce.2017.58006

Received: August 4, 2017

Accepted: October 7, 2017

Published: October 10, 2017

\begin{abstract}
Objectives: To challenge the expiry dates of low concentration high purity mycotoxins standards. Literature Review: Aflatoxins (AFs) and Ochratoxin A (OTA) are persistent mycotoxins with adverse effects on humans. Mycotoxins standards are purchased to determine mycotoxin concentrations in food and may be stocked in some laboratories beyond expiry dates causing laboratories financial losses. Methods: Certified mycotoxins standards were purchased over the years from the same supplier at times and at other times from two different suppliers for quality control purposes. For AFs, six chromatographic runs for each of the mycotoxins standards were done to compare the difference among these standards having the following expiry dates (2008, 2012, 2013 and 2018). AFs standards purchased/obtained from two different suppliers in 2016 and expiring in 2018 were also compared. For OTA, the difference of concentration obtained between two years (2010 and 2018) was tested. All samples were run on a HPLC equipped with a fluorescence detector. Linearity of calibration curves and the points of lowest detection were determined for AFs components and for OTA from the unexpired mycotoxins standards. Results: At a 0.05 significance level and using non parametric tests, the statistical test revealed a $\mathrm{p}$ of $0.166,0.153,0.358$ and 0.03 for B1, G1, B2 and G2 respectively among years for standards from same supplier and $\mathbf{0 . 0 3 7}$, $0.109,0.182$ and 0.182 for B1, G1, B2 and G2 respectively for unexpired standards from two different suppliers. For OTA, a p of 0.109 was obtained for standards of different expiry dates purchased from different suppliers. Conclusion: High purity low concentration mycotoxin standards purchased a decade ago (i.e. expired) did not differ from those purchased this current year (still valid). Hence, the expiry date can be renewed reducing the laboratories expenses. Manufacturers are urged to reconsider the expiry dates.
\end{abstract}




\section{Keywords}

Mycotoxins, Aflatoxins, Ochratoxin A, G1, G2, B1, B2, OTA, Persistent, Thermostable, Standards, Certified, Low Concentration, High Purity, Challenge, Expiry Date, Years, HPLC, Manufacturer, Suppliers

\section{Introduction}

Aflatoxins and Ochratoxin A (Figure 1 \& Figure 2) [1], persistent and thermostable natural mycotoxins produced by fungi [2] [3], are found in different foodstuffs such as peanuts, corn, coffee beans and spices [4]. Aflatoxins are composed mainly of G2, B2, G1 andB1toxins; the latter has been classified as a carcinogen [5].

Mycotoxins have adverse effects on human health. They alter the mitochondrial DNA, affect protein synthesis, damage the blood cell production, blood components, kidneys and liver [6] [7] [8]. Because of their harmful effect and because the main route of mycotoxins into the human body is through ingestion of contaminated food [9], it became imperative to measure their concentration in food matrices. For this, high purity standards (greater than 98\%) containing specific concentration of mycotoxins were purchased or obtained.

Both AFs and OTA standards come often in low concentration with specific expiry dates which is usually within two years of production and/or date of opening. By definition, expiry date is the date after which the standard is not valid to be used [10]. In other words, when a standard is expired, it must not be used since the results might not be accurate or defensible. For the suppliers of these standards, regulatory and economic factors affecting the determination of the expiry date, include the accuracy and precision of the manufacturer in studying the stability of compounds, the storage conditions as well as the ability of the manufacturer to sell more chemicals which increases the laboratory expenses

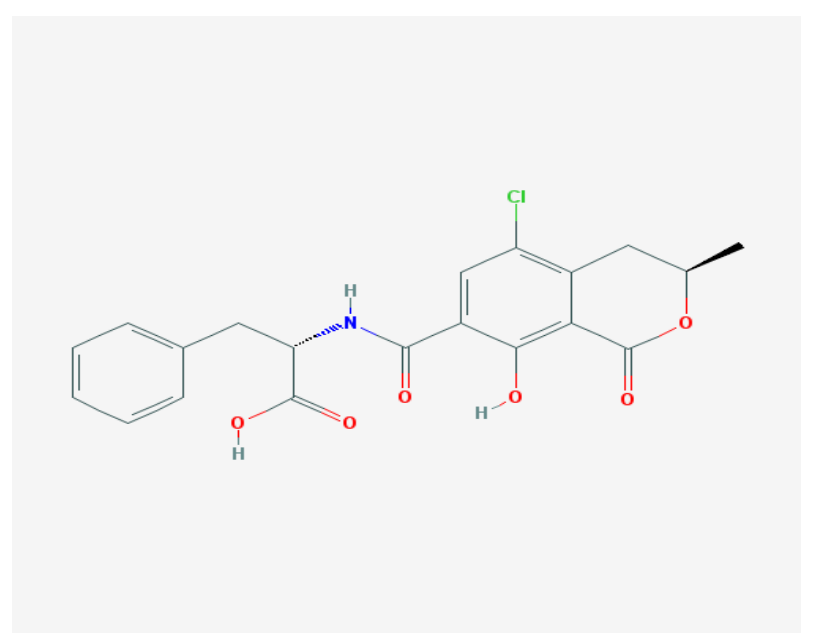

Figure 1. Structure of OTA according to PubChem-NIH [1]. 


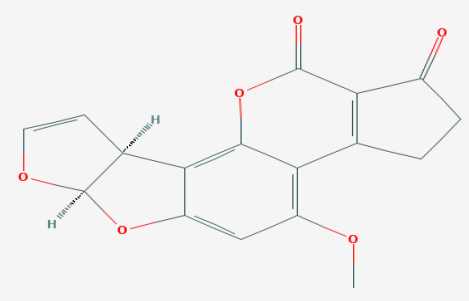

Structure of AF B1

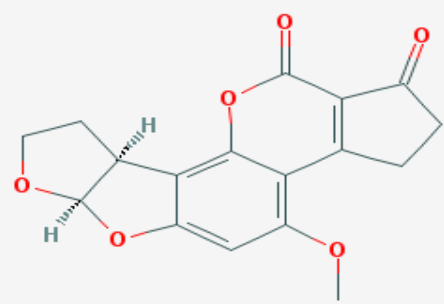

Structure of AF B2

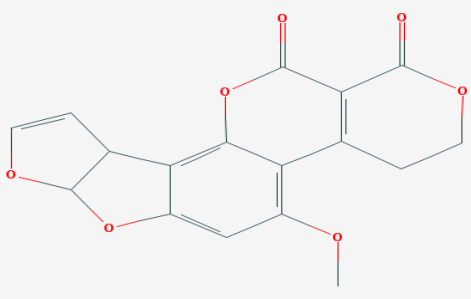

Structure of AF G1

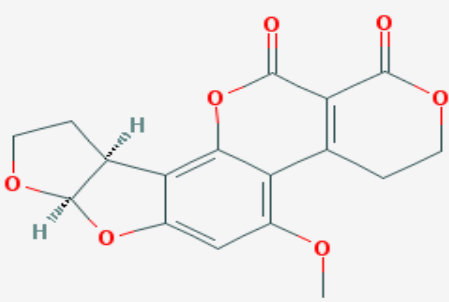

Structure of AF G2

Figure 2. Structures of AF components according to PubChem-NIH [1].

[11] especially for laboratories already working under tight budgets. In addition to this, laboratories have to purchase the standards periodically and might not use all its standard stock within the expiry date. This will incur on the laboratories financial losses and any saving in this matter will minimize the expenses and shortens the quantity of chemicals stored for disposal purposes.

In this paper, trials were conducted in order to challenge the expiry dates and to check if properly stored $\left(4^{\circ} \mathrm{C}\right)$ low concentration high purity mycotoxins' standards, specifically B1, B2, G1, G2 and OTA can last for many years even at low doses without being affected by time and can be preserved for at least a decade without degrading. This study will save the laboratories some financial losses and will help or prompt the suppliers to rethink and extend their expiry date.

\section{Experiment}

Materials. Certified high purity low concentration standards were purchased or obtained over the following years (2006, 2010, 2011 and 2016) for AFs and over two years (2008 and 2015) for OTA. In the year 2016, AFs standards, tested from two different suppliers, were at a concentration of $0.3 \mu \mathrm{g} / \mathrm{ml}$ for B1 and G1 and 1 $\mu \mathrm{g} / \mathrm{ml}$ for B2 and G2 for the standard obtained from the first supplier; and 0.5 $\mu \mathrm{g} / \mathrm{ml}$ for B1 and G1 and $2 \mu \mathrm{g} / \mathrm{ml} \mathrm{B} 2$ and G2 for the standard purchased from the second supplier. For OTA, standards purchased or obtained, were from two different suppliers at a concentration of $1 \mu \mathrm{g} / \mathrm{ml}$. Standards were all processed at the Environmental Core Laboratory of the American University of Beirut. High 
purity solvents mainly acetonitrile (Sigma-Aldrich) and methanol (Sigma-Aldrich) were used. As for derivatization of AFs, a solution of water, trifluoroacetic acid (Sigma-Aldrich) and glacial acetic acid (AnalaR) in a ratio of 7:2:1 was used. Equipment, programs \& experiments. HPLC (Agilent, 1100 series), equipped with FLD (Agilent Technologies, 1200 series), was used for AFs and OTA analyses. The mobile phase, used in the detection of AFs, was prepared by mixing water, methanol and acetonitrile in a ratio of 6:2:2. As for mobile phase of OTA, acetonitrile was mixed with water and glacial acetic acid in a ratio of 99:99:2. All samples were filtered $(0.45 \mu \mathrm{m})$ before $20 \mu \mathrm{l}$ of each vial was injected in the instrument using an auto sampler. In order to check on the precision and reproducibility of sample injection, and to eliminate the chance that the difference among samples is coming from a defect in the auto sampler/injection and/or needle, a curve of certified series of standards of caffeine concentrations $(5,25$, 50, 125 and $250 \mu \mathrm{g} / \mathrm{ml}$ ), purchased from Agilent, was used. AFs and OTA components were separated using the C-18column (Hypersil, particle size $5 \mu \mathrm{m}$, dimensions $250 \mathrm{~mm} \times 4.6 \mathrm{~mm}$ ). Moreover, due to their ability to fluoresce, AFs and OTA were detected using fluorescence detector (FLD) where AFs excitation was at $365 \mathrm{~nm}$ wavelength and emission was at $450 \mathrm{~nm}$ [12]. As for OTA, the excitation was at $333 \mathrm{~nm}$ and the emission was at $460 \mathrm{~nm}$ [4]. Finally, the data was displayed on the computer connected to the HPLC system (Chemstation for LC 3D system).

Calibration curves and quality control preparation. The first step was to establish calibration curves of six points (Table 1) for each of the two AF standards purchased/obtained in 2016 (expiry date 2018) from two different suppliers to ensure a good quality control [13] i.e. to make sure that there is no difference between suppliers. This was done to eliminate any chance that the difference in standards among years is not stemming from difference in suppliers concentrations or stocks but rather from the degradation of the analytes themselves. This can become the case if we were to compare expired standards from one supplier with a currently valid standard purchased from a different supplier. The second step was to determine the lowest quantification point for each and every mycotoxin component. This was done to check, by the same token, the limitation of the method, to reaffirm the ability of the laboratory to meet safety limits values especially for B1 (less than $1 \mathrm{ppb}$ ) and for G1, G2 and B2 (less than $0.5 \mathrm{ppb}$ ) and to report below these lowest detection points in case of degradation

Table 1. Six different concentrations of AFs components used in the calibration curves and diluted from high purity low concentration original standard where the original stock from one supplier contained different concentrations of individual: $1000 \mathrm{ppb}$ for G1 and $\mathrm{B} 1$ and $300 \mathrm{ppb}$ for $\mathrm{B} 2$ and G2 mycotoxins.

\begin{tabular}{cccccccc}
\hline & Standard 1 & Standard & Standard & Standard & Standard & Standard \\
& & 2 & 3 & 4 & 5 & 6 \\
\hline G1 and B1 (ppb) & 2.2 & 3.3 & 4.4 & 6.6 & 13.2 & 26.4 \\
G2 and B2 (ppb) & 0.67 & 1.005 & 1.34 & 2 & 4 & 8 \\
\hline
\end{tabular}


of standards. Standard calibration curves were prepared and processed from a stock of $1000 \mathrm{ppb}$ for B1 and G1; and $300 \mathrm{ppb}$ for B2 and G2 according to the protocol highlighted in the next paragraph. For OTA, five different concentrations $(0.5,2,4,6$ and $8 \mathrm{ppb})$ were prepared from an original stock of $1000 \mathrm{ppb}$. Both sets of curves (AF components and OTA) were repeated three times. A coefficient of correlation(r), greater than 0.995, was accepted for both AFs and OTA.

AFs and OTA preparation for standard comparison testing. Six different aliquots, taken from each standard container, were each transferred to individual chromatography micro vials. AF samples were evaporated to dryness using nitrogen gas (purity 99.999\%). For derivatization, $0.6 \mathrm{ml}$ of acetonitrile and $1.2 \mathrm{ml}$ of derivatizing mixture were added to the AFs vials only. Samples were then placed in an incubator at $65^{\circ} \mathrm{C}$ for 9 minutes before injecting the samples on HPLC system [12] [14]. The final concentration for the six determinations of B1 and G1 was 26.4 ppb while it was 8 ppb for B2 and G2 in all samples (Table 1). As for OTA samples, dilutions from the original stock (1000 ppb) were prepared using a mixture of acetonitrile, water, and glacial acetic acid (99:99:2, v/v/v). The concentration of OTA obtained was $1.8 \mathrm{ppb}$ for all samples.

Statistical analysis. Areas under the individual peaks of each standard were recorded. Data was manipulated using excel and statistical analyses were done using SPSS (version 24). The nonparametric Kruskal-Wallis test was performed with a confidence level of $0.05 \%$ on AF individual toxins in order to check whether there is a significance difference between expired and unexpired AFs standards stocked from different years and purchased from same supplier. Kruskal-Wallis was also performed on the unexpired AF standards obtained from the two different suppliers and purchased in 2016. It was also applied to detect difference in years for OTA standards even though those were purchased from two different suppliers. It is worth mentioning that with OTA standards, any difference which might arise between years and suppliers will be perhaps due to either a difference between the suppliers themselves or a degradation between the two years (a decade apart). Null hypothesis is retained when there is no statistical significant difference between the samples while it is rejected when significant difference exist and the probability of the difference is less than 1 in $20(5 \%$ or 0.05$)$.

\section{Results and Discussion}

Results are reported per individual mycotoxins. Calibration curves for caffeine, OTA and AFs components were visually assessed and their linearity was accepted since the correlation coefficient was greater than 0.995 for all of them (Table 2).

Calibration curves. The HPLC instrument was eliminated as a cofactor which might have affected the analytical and statistical outcomes since accuracy and precision in injection were achieved. The instrument was able to detect low and high concentrations of mycotoxins and the linearity of caffeine calibration 
Table 2. Correlation coefficient (r), limit of quantification (LOQ in $\mathrm{ppb}$ ) and equation of the calibration curve for each of B1, G1, B2, G2, OTA and caffeine extracted from the calibration curves.

\begin{tabular}{cccc}
\hline Mycotoxins and Caffeine & $\mathrm{r}$ & LOQ $(\mathrm{ppb})$ & Equation of calibration curve \\
\hline B1 & 0.9989 & 2.2 & $\mathrm{y}=4.3005 \mathrm{x}-3.1197$ \\
G1 & 0.998 & 2.2 & $\mathrm{y}=2.0981 \mathrm{x}-1.5463$ \\
B2 & 0.9993 & 0.67 & $\mathrm{y}=4.9284 \mathrm{x}-0.0352$ \\
G2 & 0.9976 & 0.67 & $\mathrm{y}=3.1662 \mathrm{x}-0.4517$ \\
OTA & 0.9992 & 0.5 & $\mathrm{y}=0.3474 \mathrm{x}-0.0439$ \\
caffeine & 0.9988 & 5 & $\mathrm{y}=66.627 \mathrm{x}+272.25$ \\
\hline
\end{tabular}

curve $(r=0.9988)$ (Figure 3) eliminates the chance that the difference among mycotoxins samples, if found, is coming from a defect in the auto sampler/ injection and/or needle rather than degradation of samples through time.

Moreover, high correlation coefficients (r) 0.9989, 0.998, 0.9993, 0.9976, and 0.9992 for B1, G1, B2, G2 and OTA, from unexpired standards and from two suppliers, were obtained respectively (Figure 4).

Comparison results. Areas under chromatograms were extracted from the software outputs and median, mean, standard deviation (SD) and range were calculated for each mycotoxin component (Table 3).

AFs difference between two suppliers same year of purchase (2016) and same year of expiry (2018). The statistical test for comparing AF standards purchased from two different suppliers, having the same expiry date (2018), revealed a $\mathrm{p}$ of $\mathbf{0 . 0 3 7}, 0.109,0.182$ and 0.182 for $\mathrm{B} 1, \mathrm{G} 1, \mathrm{~B} 2$ and G2 respectively at a 0.05 confidence level. As a result, null hypothesis is retained for AFs components (except for B1) and there is no significant difference between AF standards from two different suppliers. Since these standards are not expired yet and since the difference appears only for B1, and only among suppliers, it is then safe to say that this difference is not due to degradation. Any future difference among years with B1, if found, will be looked at closely, especially when expired B1 from one supplier (for years 2008, 2012 and 2013) was compared with an unexpired B1 from another supplier yielded a $\mathrm{p}$ of $\mathbf{0 . 0 4 7}$ which is on borderline (The difference between means was less than 9\%). As a result, the difference is not related to degradation but most probably it is due to a natural difference between suppliers.

AFs standards difference among years purchased from same supplier. AFs standards purchased from same supplier expiring in 2008, 2012, 2013 and 2018 were compared among each other. The statistical test showed a $\mathrm{p}$ of $0.166,0.153$, 0.358 and $\mathbf{0 . 0 3}$ for B1, G1, B2 and G2 respectively. For G2, the area obtained for year 2012 was greater than that of years 2013 and 2018. Consequently, the significance difference was not due to degradation, it might due to other reasons (analytical, difference in preparation of batches, integration of peaks, etc.).Thus, null hypothesis was retained for all AFs components. Therefore, expired AF 
standards, belonging to same supplier, did not differ from newly purchased ones (still valid, unexpired).

OTA standard difference among years obtained from two different suppliers. For OTA, standards obtained from two different suppliers with different expiry dates (2010 and2018) were compared and statistical test revealed a p of 0.109. Therefore, null hypothesis was retained and OTA standards are considered persistent and did not expire for at least a decade in this study. However, this remains true for the OTA if we keep our original assumption that there exists no difference between suppliers to start with. And, if this assumption does not hold true, i.e. if the concentrations of OTA in unexpired standards between

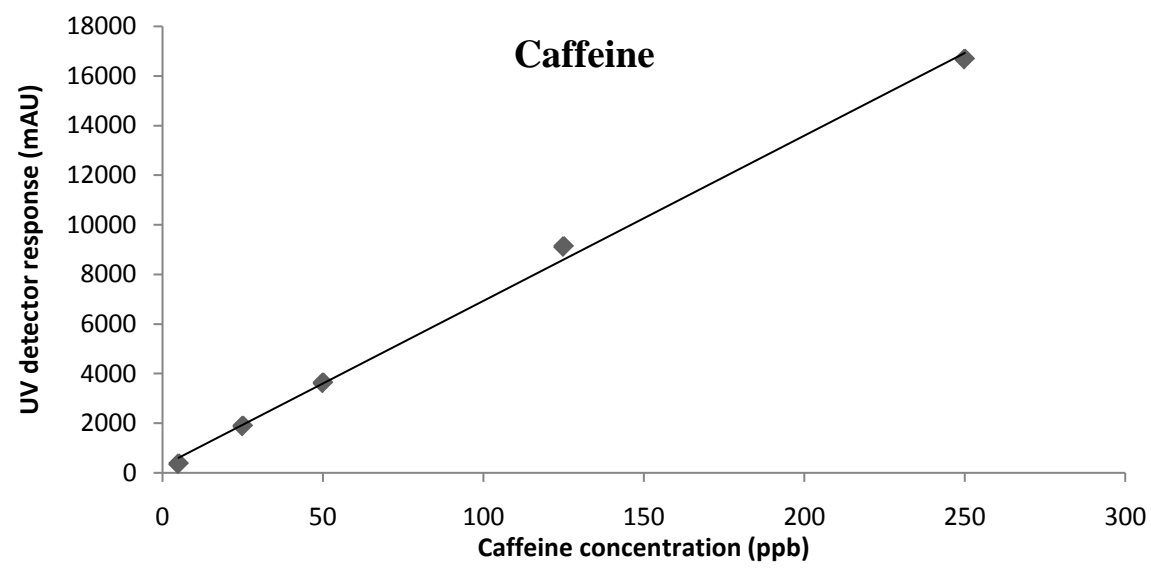

Figure 3. Caffeine standard curve for checking precision and accuracy of HPLC components.

Table 3. Mean \pm SD, median, range (min-max)of areas under peaks and $\mathrm{p}$ value for mycotoxins purchased from the 2 different suppliers with various expiry dates using Kruskal-Wallis test ( $\mathrm{p}$ is significant $<0.05$ ).

\begin{tabular}{|c|c|c|c|c|c|c|c|c|}
\hline & & \multicolumn{4}{|c|}{ Supplier 1} & Supplier 2 & \multicolumn{2}{|c|}{$\mathrm{p}$ value } \\
\hline \multicolumn{2}{|c|}{ Mycotoxins } & $\begin{array}{l}\text { AFs } 2008 \\
\text { OTA } 2010\end{array}$ & 2012 & 2013 & 2018 & 2018 & $\begin{array}{l}\text { Among } \\
\text { suppliers } \\
(1 \text { and } 2)\end{array}$ & Among years \\
\hline \multirow[b]{2}{*}{ AFB1 } & Mean \pm SD & $85.75 \pm 16.02$ & $98.37 \pm 6.60$ & $83.82 \pm 7.80$ & $84.05 \pm 12.48$ & $105.05 \pm 16.42$ & \multirow[b]{2}{*}{0.037} & \multirow[b]{2}{*}{0.166} \\
\hline & $\begin{array}{c}\text { Median } \\
(\min -\max )\end{array}$ & $\begin{array}{c}88.90 \\
(61.3-104.65)\end{array}$ & $\begin{array}{c}99.29 \\
(91-107.91)\end{array}$ & $\begin{array}{c}80.05 \\
(77.34-94.58)\end{array}$ & $\begin{array}{c}81.55 \\
(70.11-107.37)\end{array}$ & $\begin{array}{c}110.46 \\
(71.93-114.68)\end{array}$ & & \\
\hline \multirow[b]{2}{*}{ AFB2 } & Mean \pm SD & $34.98 \pm 7.26$ & $34.89 \pm 2.39$ & $30.27 \pm 4.96$ & $31.82 \pm 5.35$ & $36.53 \pm 5.49$ & \multirow[b]{2}{*}{0.182} & \multirow[b]{2}{*}{0.358} \\
\hline & $\begin{array}{c}\text { Median } \\
(\min -\max )\end{array}$ & $\begin{array}{c}36.35 \\
(24.66-42.79)\end{array}$ & $\begin{array}{c}35.14 \\
(30.68-37.78)\end{array}$ & $\begin{array}{c}29.42 \\
(23.80-36.99)\end{array}$ & $\begin{array}{c}30.66 \\
(25.85-41.79)\end{array}$ & $\begin{array}{c}38.70 \\
(25.42-39.85)\end{array}$ & & \\
\hline \multirow[b]{2}{*}{ AFG1 } & Mean \pm SD & $38.21 \pm 16.01$ & $52.27 \pm 4.89$ & $38.91 \pm 7.60$ & $38.03 \pm 7.92$ & $48.45 \pm 8.42$ & \multirow[b]{2}{*}{0.109} & \multirow[b]{2}{*}{0.153} \\
\hline & $\begin{array}{c}\text { Median } \\
(\min -\max )\end{array}$ & $\begin{array}{c}39.09 \\
(18.8-55.5)\end{array}$ & $\begin{array}{c}52.27 \\
(46.87-58.12)\end{array}$ & $\begin{array}{c}36.96 \\
(31.55-48.89)\end{array}$ & $\begin{array}{c}37.25 \\
(30.26-51.09)\end{array}$ & $\begin{array}{c}50.14 \\
(32.50-57.77)\end{array}$ & & \\
\hline \multirow[b]{2}{*}{ AFG2 } & Mean \pm SD & $19.15 \pm 6.96$ & $25.78 \pm 1.87$ & $18.66 \pm 2.94$ & $19.11 \pm 3.89$ & $22.17 \pm 3.22$ & \multirow[b]{2}{*}{0.182} & \multirow[b]{2}{*}{0.030} \\
\hline & $\begin{array}{c}\text { Median } \\
(\min -\max )\end{array}$ & $\begin{array}{c}19.42 \\
(11.06-27.09)\end{array}$ & $\begin{array}{c}25.61 \\
(23.89-28.29)\end{array}$ & $\begin{array}{c}19.14 \\
(14.97-22.13)\end{array}$ & $\begin{array}{c}17.09 \\
(16.38-25.97)\end{array}$ & $\begin{array}{c}23.24 \\
(16.02-25.09)\end{array}$ & & \\
\hline \multirow[b]{2}{*}{ OTA } & Mean \pm SD & $0.64 \pm 0.11$ & --- & --- & --- & $0.46 \pm 0.11$ & \multirow[b]{2}{*}{---} & \multirow[b]{2}{*}{0.109} \\
\hline & $\begin{array}{c}\text { Median } \\
(\text { min-max) }\end{array}$ & $\begin{array}{c}0.61 \\
(0.53-0.84)\end{array}$ & --- & --- & -- & $\begin{array}{c}0.45 \\
(0.21-0.59)\end{array}$ & & \\
\hline
\end{tabular}


B1
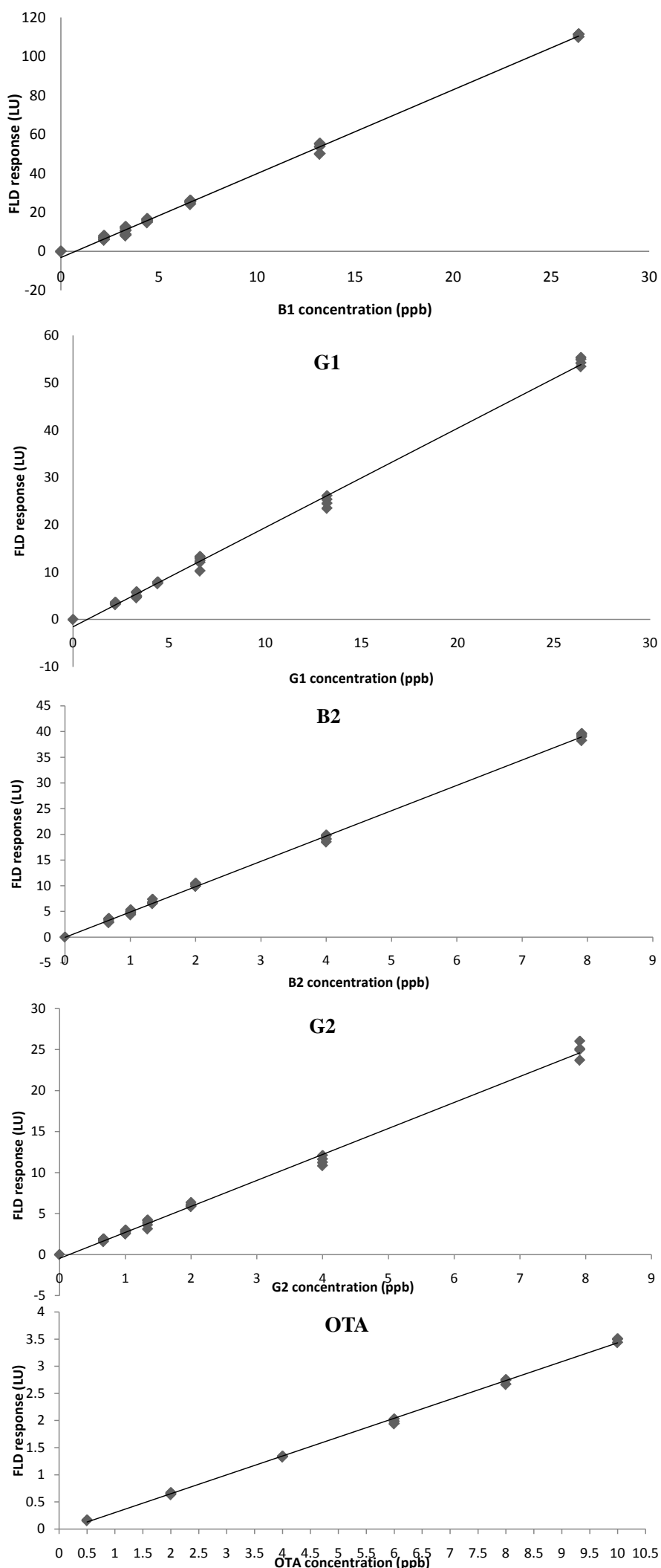

Figure 4. Calibration curves forB1, G1, B2, G2, and OTA taken from two different suppliers and repeated three times. 
suppliers are different, then the insignificant statistical $\mathrm{p}$ cannot be interpreted to conclude that the OTA did not degrade. In this case we say either there was no difference between suppliers and OTA did not degrade, or alternatively there is difference between two suppliers and hence we cannot truly conclude if the OTA has degraded or not. In this case, as a corrective action, it is advisable to purchase additional OTA standards from three other suppliers at least.

Consequently, high purity low concentration AFs and OTA standards are persistent and do not degrade for at least a decade. This study is a small contribution and means to help laboratories in cost savings by reducing the expenses of buying new standards or getting rid of expired ones which might involve shipping fees and disposal penalty. Moreover, it will hopefully help the manufacturers to extend the expiry date of mycotoxins standards mainly AFs and OTA and update their way in determining them. It is worth mentioning that to the best of our knowledge this is the first study done to challenge the expiry date of mycotoxins standards stored over a decade.

\section{Conclusion}

The study confirmed that AFs and OTA were persistent and that the challenge of expiry dates was successful as none of the mycotoxins components B1, G1, B2, G2 and OTA degraded over the last decade taking into consideration all the other cofactors that may have affected the study (HPLC instrument, analyst, storage of standards) and the assumption made to the OTA. Thus, manufacturers are urged to rethink the way they determine the expiry date of mycotoxin standards. This study is beneficial for laboratories since it reduces their expenses.

\section{References}

[1] Online Reference. https://pubchem.ncbi.nlm.nih.gov

[2] Brewer, J.H., Thrasher, J.D. and Hooper, D. (2013) Chronic Illness Associated with Mold and Mycotoxins: Is Naso-Sinus Fungal Biofilm the Culprit? Toxins, 6, 66-80. https://doi.org/10.3390/toxins6010066

[3] Vidal, A., Sanchis, V., Ramos, A.J. and Marin, S. (2016) The Fate of Deoxynivalenol through Wheat Processing to Food Products. Current Opinion in Food Science, 11, 34-39. https://doi.org/10.1016/j.cofs.2016.09.001

[4] FAO/IAEA Training, Reference Centre for Food, and Pesticide Control (2001) Manual on the Application of the HACCP System in Mycotoxin Prevention and Control. Food \& Agriculture Org., No. 73.

[5] IARC Working Group on the Evaluation of Carcinogenic Risks to Humans, IARC Monographs on the Evaluation of Carcinogenic Risks to Humans, World Health Organization and International Agency for Research on Cancer (2002) Some Traditional Herbal Medicines Some Mycotoxins, Nephthalene and Styrene (No. 82). World Health Organization.

[6] Bbosa, G.S., Kitya, D., Lubega, A., Ogwal-Okeng, J., Anokbonggo, W.W. and Kyegombe, D.B. (2013) Review of the Biological and Health Effects of Aflatoxins on Body Organs and Body Systems, Chapter 12 of the open access book: Aflatoxins-Recent Advances and Future Prospects, ed. Mehdi Razzaghi-Abyaneh. http://www.intechopen.com/books/aflatoxins-recent-advances-and-future-prospects 
[7] Denli, M. and Perez, J.F. (2010) Ochratoxins in Feed, a Risk for Animal and Human Health: Control Strategies. Toxins, 2, 1065-1077. https://doi.org/10.3390/toxins2051065

[8] Alassane-Kpembi, I., Schatzmayr, G., Taranu, I., Marin, D., Puel, O. and Oswald, I.P. (2017) Mycotoxins Co-Contamination: Methodological Aspects and Biological Relevance of Combined Toxicity Studies. Critical Reviews in Food Science and Nutrition, 57, 3489-3507. https://doi.org/10.1080/10408398.2016.1140632

[9] Assunção, R., Silva, M.J. and Alvito, P. (2016) Challenges in Risk Assessment of Multiple Mycotoxins in Food. World Mycotoxin Journal, 9, 791-811. https://doi.org/10.3920/WMJ2016.2039

[10] World Health Organization (2016) WHO Expert Committee on Specifications for Pharmaceutical Preparations: Fiftieth Report (Vol. 996). World Health Organization.

[11] Phifer, P.W. (September/October 1999) Reagent Expiration Dates: Fact or Fiction? Chemical Health \& Safety, 6, 17-20. https://doi.org/10.1016/S1074-9098(99)00030-1

[12] Trombete, F.M., Moraes,D.dA., Porto, Y.D., Santos, T.B., Direito, G.M., Fraga, M.E. and Saldanha, T. (2014) Determination of Aflatoxins in Wheat and Wheat By-Products Intended for Human Consumption, Marketed in Rio de Janeiro, Brazil. Journal of Food and Nutrition Research, 2, 671-674. https://doi.org/10.12691/jfnr-2-10-3

[13] BRITISH STANDARD BS ISO 11095:1996 Implementation of ISO 11095: 1996 LINEAR Calibration Using Reference Materials.

[14] Wacoo, A.P., Wendiro, D., Vuzi, P.C. and Hawumba, J.F. (2014) Methods for Detection of Aflatoxins in Agricultural Food Crops. Journal of Applied Chemistry. 